\title{
Nudging College Pre-service Teachers towards the Desired Path in Isomerism Concepts of Aliphatic Hydrocarbons through the Use of Conceptual Change Texts
}

\author{
Woldie Belachew ${ }^{1^{*}}$ \\ ${ }^{1}$ Addis Ababa University, ETHIOPIA \\ Received 22 May 2019 - Revised 29 August 2019 - Accepted 3 September 2019
}

\begin{abstract}
The main objective of the study was to determine Pre-service Chemistry Teachers' (PCTs) understanding of isomerism related concepts of Aliphatic Hydrocarbons (AHs). To get in-depth picture of PCTs understanding on isomerism related concepts of AHs, case study was employed. The sample for this study consisted of twelve participants selected from 87 PCTs randomly, in two classes. These were second year PCTs registered in Introductory Organic Chemistry I course in Arbaminch College of Teachers Education, Southern, Nations, Nationalities and Peoples Regional State (SNNPRS), Ethiopia in the year 2017 G.C. A semi-structured interview was used for judging understanding of PCTs in relation to isomerism concepts. A framework analysis approach was applied to analyze interview data. The results of analysis revealed that the PCTs in the Intervention Group (IG) had better acquisition of isomerism concepts than those in the Comparison Group (CG). Based on the results and discussions, conclusions were made.
\end{abstract}

Keywords: hydrocarbons, conceptual change, isomerism

\section{INTRODUCTION}

Literature search (Johnstone, 2006; Johnstone, 2010; O’Dwyer \& Childs, 2017) indicated that organic chemistry, in general, is difficult for college level learners. Learners face difficulty almost in all concepts of introductory organic chemistry (O'Dwyer \& Childs, 2017). Isomerism is one piece of introductory organic chemistry concepts. The existence of isomerism related nuances have been reported in different research papers (Bryan, 2007; Taagepera \& Noori, 2000; Schmidt, 1992; Sendur, 2012). Students have limited understanding in relation to isomerism (Taagepera \& Noori, 2000; Schmidt, 1992). For instance, learners' conception indicated that isomerism is limited to compounds of the same class (Schmidt, 1992). Also, there are learners who perceive isomers as having the same shape in their representations (Taagepera \& Noori, 2000). As indicated by Sendur (2012) boiling points of geometric isomers are the same because geometric isomers have the same chemical formulas. According Bryan (2007) as long as there is a $\mathrm{C}=\mathrm{C}$ bond with two different groups on each side of the double bond, it can display cis-trans isomerism. Instructional approaches, such as conceptual change, approach have the potential to correct/remediate alternative conceptions indicated in here.

Conceptual change is becoming popular in science education nowadays. Conceptual change is conceived by and an offspring of cognitive psychology (Gorodetsky, \& Keiny, 2002). It was introduced by Thomas Kuhn (1962) to designate that the concepts well-established in a scientific theory change their meaning when the paradigm changes. The meaning of conceptual change has changed since its inception and it is an evolving arena, even today. Clement (2008) describes a range of types of conceptual change like modifying an existing model by adding, removing, or changing elements; creating a new model; or replacing a concept with an ontologically different concept. Also, Mayer views it as the means underlying meaningful learning (Mayer, 2002). Conceptual change is a learning process in which students' alternative conceptions change or renovate into the intended scientific conceptions (Vosniadou, 2007). It is an outgrowth of constructivist epistemology in which knowledge acquirement

(c) 2020 by the authors; licensee Modestum Ltd., UK. This article is an open access article distributed under the terms and conditions of the Creative Commons Attribution License (http://creativecommons.org/licenses/by/4.0/). \woldbe@yahoo.com (*Correspondence) 


\section{Contribution of this paper to the literature}

- This study examines the understanding of learners in the conceptual change text-based instruction group and those in the traditional text-based instruction group in relation to isomerism. Results were generated and discussed were made in detail.

- Themes were generated based on responses of participants and literature search. These themes served as a stepping-stone for discussion and conclusion made in this study.

- The alternative conceptions and correct conceptions of learners reflected, thematized and used during analysis have indicated the fact that teachers should emphasize on meaningful learning with understanding.

is viewed as a constructive process that involves actively generating and testing alternative propositions (Tyson, Venville, Harrison \& Treagust, 1997). Conceptual change takes place when a learner makes a shift from not understanding how something works to understanding it (Mayer, 2002), but this view has been questioned by conceptual change researchers who took position on coexistence of concepts (Vosniadou, 2007, Vosniadou \& Skopeliti, 2014). There are different strategies in conceptual change approach, among which conceptual change texts are worth mentioning.

Conceptual change texts are different from traditional texts. Traditional science texts are tricky for student to learn meaningfully because most are full of technical terms, which are very difficult to comprehend (Graesser, Leon \& Otero, 2002). This is associated with the problem of text book writers (Graesser et al., 2005). Choosing the right strategy such as the use of CCT is suggested in science education literature (Özkan \& Selçuk, 2012; Sendur, 2012; She, 2003; Sendur \& Toprak, 2013). Preferring the right strategy to be used in the organic chemistry courses at college level may require applying the constructivist approach to bringing conceptual understanding. This entails using texts, which can make learning more meaningful. Instruction based on constructivist approach focuses on students' ideas, encourages students to think about situations, and use their knowledge and share their ideasmaking students active in the learning process (Duffy \& Jonassen, 1991; Brooks \& Brooks, 1993; Tam, 2000). Conceptual change texts (CCTs) with alternative conceptions of learners, reasons for correct responses, justifications for alternative or nuanced ideas and sufficient examples (Guzzetti et al, 1997) satisfy the requirements of constructivists' view. CCTs present new theories to refute the old ones (Özkan \& Selçuk, 2012). CCTs are particularly effective in promoting conceptual change. These texts contrast common alternative conceptions with scientific conceptions. CCTs occur naturally in some science textbooks (Swafford, 1989), but most often can be constructed by researchers in education (Alvermann \& Hague, 1989; Maria \& MacGinitie, 1987) or science education (Roth, 1986). The usefulness of CCT has been confirmed in many studies (Başer, 2006; Başer \& Geban, 2007; Özkan \& Selçuk, 2012; She, 2003; Sendur \& Toprak, 2013). These texts always start with a question to activate misconception in the students' minds. Then, the most commonly used misconceptions concerning that topic are presented, and students are convinced why they are wrong by giving them various evidences. Here, the purpose is to enable students to question those concepts and see the inadequacy of what they know. In relation to this, there is evidence that well-structured texts have the tendency to be remembered with ease (Wylie \& McGuinness, 2004).

However, there is limited study that focuses on determining the effect of CCT- based instruction in understanding basic concepts in organic chemistry (Sendur \& Toprak, 2013). Thus, this study is sought to spot the effectiveness of conceptual change approach through the use of CCT on isomerism related aliphatic hydrocarbon concepts.

\section{OBJECTIVE AND RESEARCH QUESTIONS}

The overriding aim of the study was to look in to pre-service chemistry teachers' understanding of isomerism related concepts of aliphatic hydrocarbons. To achieve this major purpose the following research questions were addressed:

1. How do pre-service chemistry teachers understand isomerism related concepts of AHs before running conceptual change (through the use of CCTs) and conventional instructional approaches?

2. How do pre-service chemistry teachers understand isomerism related concepts of AHs after running conceptual change (through the use of CCTs) and conventional instructional approaches?

3. Is there change in understanding isomerism related $\mathrm{AH}$ concepts after running conceptual change (through the use of CCTs) and conventional instructional approaches? 


\section{METHODOLOGY}

\section{Case Study}

To get intensive portrayal of pre-service chemistry teachers understanding on isomerism related concepts of AHs, case study was employed. Case study has been used as effective qualitative research approach in different studies. For example, case study was used to illuminate the alignment or inconsistencies between espoused theories of learning and practices in the classroom (Lyons, Freitag \& Hewson, 1997), to understand the role of reflection upon the teacher's development and classroom practice (Sweeney, Bula \& Cornett, 2001), and use of models in understanding chemistry concepts (Harrison \& Treagust, 2000). So, to have a better grasp of conceptual understanding of the case (second year pre-service teachers taking organic chemistry I) the researcher adhered to case study approach. The case could be regarded as the case of second year pre-service chemistry teachers in relation to conceptual understanding of isomerism related $\mathrm{AH}$ concepts. This fits well with literature in case study (Ary, Jacobs, Sorensen \& Razavie, 2010). As posited by Ary et al. (2010) case study focuses on a single unit, such as one individual, one group, one organization, or one program.

\section{Research Site, Population and Participants}

This study was conducted in Arbaminch College of Teachers Education, SNNPRS, Ethiopia. The participants in this study were from a convenience sample of 87 pre-service chemistry teachers, in two classes, registered in Introductory Organic Chemistry I in the same college in regular Program. The two intact classes were assigned as comparison and intervention groups. Interviews were conducted with six students from each group before and after the treatment. That is, a total of twelve randomly selected chemistry pre-service teachers participated in the qualitative interview. The composition was from students of both categories. From the six-comparison group preservice chemistry teachers two were high achievers, two were medium achievers and the remaining two were low achievers. The selection was based on previous semester GPA. Two of the comparison group participants were females. Again, from the six intervention group students two were high achievers, two were medium achievers and the remaining two were low achievers. Here also the selection was based on previous semester GPA. Two of the intervention group participants were females as well.

\section{Treatment}

Twelve PCTs selected from Eighty-seven PCTs in two classes/groups were part of this study. The intervention/treatment was for all PCTs in the group but the researcher used these twelve (six from each group) PCTs for data collection purpose. This study was conducted in seven weeks duration covering all concepts of AHs. The classroom instructor completed the intervention in three fifty-minute sessions in a week throughout the duration of the study period. The same instructor taught these groups during the intervention period. The instructor received trainings on the implementation of conceptual change-based instruction through the use of CCTs (Appendix C) before the intervention. The topic (isomerism) was covered in normal classroom sessions. No special arrangement was made for the intervention. Two text versions were used in this study in relation to isomerism related $\mathrm{AH}$ concepts. Isomerism related AHs concepts comprised alkanes, alkenes and alkynes related ideas. CCTs were used in relation to isomerism of alkanes, alkenes and alkynes. Traditional module-based texts (which address students' alternative conceptions indirectly) were used in the comparison group and conceptual change texts (which address students' alternative conceptions explicitly) were used in the intervention group. This means, the modules prepared for the course were used during the instructional process in the comparison group and conceptual change text infused instruction was employed in the intervention group.

\section{Instrument}

A semi-structured interview (Appendix A) was designed and used for assessing understanding PCTs in relation to isomerism concepts. According to Gilbert and Co-researchers, semi-structured interviews can dig out students existing misconceptions, as students bring personal meanings to the science classroom (Gilbert et al, 1985). Such interviews are used by researchers to discover the meaning structures that participants use to organize their experiences and make sense of their worlds that are often hidden from direct observation and taken for granted by them (Hatch, 2002). Semi-structured interviews are principal tools for gathering a lot of information (Solomon, 2008). 


\section{Trustworthiness and Validity of the Instrument}

For qualitative semi-structured interview part of the study trustworthiness was insured by: adopting research methods well established, providing sufficient research context, early communication with participating colleges, triangulation, using participants who are genuinely willing to take part, iterative questioning during interviews, debriefing, and examining previous research findings (Shenton, 2004). In addition, three senior instructors in the study site or college have reviewed the semi-structured interview to guarantee face and content validity. These professionals were asked to examine the content for omissions, errors, or any contradictions. The approach used in this study to ensure validity was similar with the approach in chemistry education research (Mulford \& Robinson, 2002).

\section{Pilot Study}

The semi-structured interview prepared was piloted with six participants before the main study. Piloting was for ensuring whether students can understand the interview items properly and to know the time required for the main study. Based on the pilot information the duration of the interview was estimated. Also, based on the piloting wordings of the items were revised and made simple.

\section{Procedures of Data Collection}

Interview guide was prepared for interviewing prior to intervention by the researcher. To satisfy the objective of the study, twelve pre-service chemistry teachers from intervention (six participants) and comparison group (six participants) were randomly selected for the interview. These twelve participants participated in both pre-and postinterview sessions. The participants were from students of both categories (low, medium and high achievers). Then, the researcher gave orientation to participants selected on individual basis about the nature of interview guide, confidentiality during and after completion of the study, and importance of recording during the research work. Participants consented to participate. Based on the consent obtained, audio appliance was used for recording of the interview. Participants were probed to give more ideas while interviewing.

\section{DATA ANALYSIS}

A framework analysis approach (Gale, Heath, Cameron, Rashid \& Redwood, 2013; Rabiee, 2004; Ritchie \& Spencer, 1994) was applied to analyze interview data. This was done after manual transcription beforehand. Framework analysis is a flexible tool that can be adapted for use with many qualitative approaches that aim to generate themes (Gale et al., 2013). It entails thematic analysis and then comparisons both within and between themes. Semi-structured interview data analysis was through categorizing students' alternative conceptions, identifying correct conceptions, generating frequencies and extensiveness of concepts. From the semi-structured interview data, the predetermined themes (categories of ACs) based on Skelly (1993) suggestions were pictured or conceptualized in this study.

Alternative conceptions from pre-and post-interview sessions were categorized based on the ways they were uttered by pre-service chemistry teachers. Identification of a thematic framework in relation to AHs in this article involved making judgments about meaning provided by pre-service chemistry teachers, the relevance of these meanings to mainstream chemistry concepts accepted by scientific community, and inherent connections between these meanings or ideas. These helped the researcher in keeping ideas in a common list.

Based on the science education literature (Govender \& Bekele, 2016; Osman, 2017, Sobal, 2001) results were presented using categorization of alternative concepts and identification of correct conceptions. Categorization of alternative conception in to alternative conceptions involving language, alternative conceptions involving prior knowledge and other cognitive aspects alternative conceptions was based on literature search (Skelly, 1993). In this study, frequency of ACs and COCs stands for number of times or counts a concept is mentioned. Extensiveness is the amount of information gathered in qualitative research through individual interview, focus group, or observations made (Sobal, 2001). It stands for number of individual interview responses aggregate in this study. Analysis was based on the ideas gathered from twelve participants. 
Table 1. Correct conceptions experienced by CG and IG students before intervention on Isomerism of AHs

\begin{tabular}{|c|c|c|}
\hline \multirow{2}{*}{ Concept } & CG pre & IG pre \\
\hline & \multicolumn{2}{|c|}{ Frequencies } \\
\hline 1. Alkanes exhibit isomerism & 1 & 2 \\
\hline 2. Alkenes exhibit isomerism & 2 & 2 \\
\hline 3. $\quad$ Alkynes exhibit isomerism & 2 & 2 \\
\hline 4. Isomers can have the different chemical properties & & 1 \\
\hline 5. Isomers have the same molecular formula & 3 & 2 \\
\hline 6. Isomers differ in their structures & 3 & 3 \\
\hline 7. Alkenes show geometric isomerism & 1 & 2 \\
\hline $\begin{array}{ll}\text { 8. } & \text { Alkanes show structural isomerism } \\
\end{array}$ & 1 & \\
\hline 9. Alkenes show isomerism due to structural difference & 1 & 1 \\
\hline 10. Alkynes show isomerism due to structural difference & 1 & 1 \\
\hline 11. Alkanes show position isomerism & & 1 \\
\hline 12. Alkenes show structural isomerism & 2 & \\
\hline 13. Alkenes show position isomerism & 2 & 2 \\
\hline 14. Alkenes exhibit chain isomerism & 1 & \\
\hline 15. Alkynes exhibit chain isomerism & 1 & \\
\hline 16. Alkynes show position isomerism & 1 & 1 \\
\hline Number of correct conceptions & 14 & 12 \\
\hline Extensiveness & 22 & 20 \\
\hline
\end{tabular}

\section{RESULTS}

\section{Prior Understanding of Isomerism Related Aliphatic Hydrocarbon Concepts}

RQ1. How do pre-service chemistry teachers understand isomerism related concepts of AHs before running conceptual change (through the use of CCTs) and conventional instructional approaches?

Table 1 shows pre-service chemistry teachers correct conceptions in isomerism related AH concepts. From fourteen Correct Conceptions (COCs) reported from the comparison group pre-service chemistry teachers, eight were reported only once, four were reported twice and two were reported three times by participants. Again, from twelve COCs reported from intervention group pre-service chemistry teachers, five were reported only once, six were reported twice and one COC was reported three times by participants. From the reported COCs some are explicated by majority of the participants in both groups. For example, isomers differ in their structures (50\%CG:50\% IG); isomers have the same molecular formula (50\%CG: 33\%IG); alkenes exhibit isomerism (33\%CG:33\% IG); alkynes exhibit isomerism (33\%CG:33\%IG); alkenes show position isomerism (33\%CG:33\% IG) and alkenes show geometric isomerism (17\%CG:33\%IG). This showed that before intervention the pre-service chemistry teachers showed low (as most COCs occurred once in CG and IG) but comparable correct conceptions in isomerism concepts of AHs.

Table 2 depicts alternative conceptions of AHs in relation to isomerism. In the two groups, there were 13 ACs.

Six ACs were in the comparison group and 7 were in the intervention group. No AC (from six ACs) in the comparison group was ACs-Lang type, 5 were ACs-prior K type and 1 was OCog-Asp-ACs. One of the seven ACs in the intervention group was AC-Lang type, 6 were ACs-prior K type and no OCog-Asp-ACs was acquired by participants in this group. Total ACs and ACs-prior K type were comparable. ACs-prior K type are dominant in both groups. From six Alternative Conceptions (ACs) reported from the comparison group pre-service chemistry teachers, five were reported only once and one AC was reported twice. Again, from seven ACs reported from intervention group pre-service chemistry teachers, six were reported only once and one AC was reported three times by participants. From the reported alternative ACs some are reported by significant number of participants. For example, students in comparison group were with opinion that alkanes exhibit ionization isomerism. Two (33\%) of the participants from the comparison group were with this AC before intervention. Another noteworthy AC among participants from intervention group was related to isomerism in alkynes. Participants from intervention group were with the idea that alkynes show geometric isomerism. Three $(50 \%)$ of the participants from the intervention group were with this AC before intervention. The interview responses of participants (both in terms of ACs and COCs) from comparison and intervention group before intervention showed that during the pretest the pre-service chemistry teachers had difficulties in isomerism related $\mathrm{AH}$ concepts with poor correct conceptions. 
Table 2. Alternative conceptions experienced by CG and IG students before intervention on isomerism of AHs AC of CG

Freq. AC of IG

Freq.

\begin{tabular}{|c|c|c|c|}
\hline \multicolumn{4}{|c|}{ Alternative conceptions involving Language (ACs-Lang) } \\
\hline & & $\begin{array}{l}\text { 1. Isomers can be changed into the other isomeric forms } \\
\text { through physical manipulation of a given structure } \\
\text { (Neopentane can be changed in to a different structure) }\end{array}$ & 1 \\
\hline \multicolumn{4}{|c|}{ Alternative Conceptions involving Prior Knowledge (ACs-Prior K) } \\
\hline $\begin{array}{l}\text { 1. Isomers have different molecular formula and } \\
\text { mass }\end{array}$ & 1 & 2. Alkynes show geometric isomerism & 3 \\
\hline 2. Alkane exhibit polymerization isomerism & 1 & $\begin{array}{l}\text { 3. Isomers are compounds with the same structures but } \\
\text { different molecular formula }\end{array}$ & 1 \\
\hline 3. Alkanes exhibit linkage isomerism & 1 & 4. Alkanes show geometric isomerism & 1 \\
\hline 4. Alkanes exhibit ionization isomerism & 2 & 5. Isomers have different molecular formula and mass & 1 \\
\hline 5. Alkanes exhibit ligand Isomerism & 1 & 6. Alkanes exhibit linkage isomerism & 1 \\
\hline & & 7. Alkenes show hydration isomerism & 1 \\
\hline \multicolumn{4}{|c|}{ Other Cognitive aspect Alternative conceptions (OCog-asp-ACs) } \\
\hline $\begin{array}{l}\text { 6. Alkanes have position isomers with double } \\
\text { bonds }\end{array}$ & 1 & & \\
\hline Number of ACs & 6 & & 7 \\
\hline Extensiveness of ACs & 7 & & 9 \\
\hline
\end{tabular}

Table 3. Correct conceptions experienced by CG and IG students after intervention on isomerism of AHs

\begin{tabular}{|c|c|c|}
\hline \multirow{2}{*}{ Concept } & CG post & IG post \\
\hline & \multicolumn{2}{|c|}{ Frequencies } \\
\hline 1. Alkenes exhibit isomerism & & 1 \\
\hline 2. $\quad$ Alkynes exhibit isomerism & & 1 \\
\hline 3. Isomers have the same molecular formula & 3 & 5 \\
\hline 4. Isomers differ in their structures & 3 & 6 \\
\hline 5. Cyclic alkanes show geometric isomerism & 1 & 1 \\
\hline 6. $\quad$ Alkanes show structural isomerism & 3 & 5 \\
\hline $\begin{array}{ll}\text { 7. } & \text { Alkenes show isomerism due to structural difference } \\
\end{array}$ & 1 & 1 \\
\hline 8. Alkynes show isomerism due to structural difference & 1 & \\
\hline 9. Alkanes show position isomerism & 2 & 3 \\
\hline $\begin{array}{ll}10 . & \text { Alkenes show structural isomerism } \\
\end{array}$ & 2 & 5 \\
\hline 11. Alkynes show structural isomerism & 1 & 5 \\
\hline 12. Alkenes show position isomerism & 4 & 4 \\
\hline 13. Alkenes exhibit chain isomerism & 1 & \\
\hline 14. Alkynes exhibit chain isomerism & 1 & \\
\hline 15. Alkynes show position isomerism & 2 & 3 \\
\hline 16. Alkenes show geometric isomerism & 3 & 4 \\
\hline Number of correct conceptions & 14 & 13 \\
\hline Extensiveness & 28 & 44 \\
\hline
\end{tabular}

\section{Isomerism Related Aliphatic Hydrocarbon Concepts Understanding after Intervention}

RQ2. How do pre-service chemistry teachers understand isomerism related concepts of AHs after running conceptual change (through the use of CCTs) and conventional instructional approaches?

Table 3 shows pre-service chemistry teachers correct conceptions in isomerism related AHCs after intervention. From fourteen Correct Conceptions (COCs) reported from the comparison group pre-service chemistry teachers, six were reported only once, three were reported twice, four were reported three times and only one COC was reported four times by participants. Again, from thirteen COCs reported from intervention group pre-service chemistry teachers, four were reported only once, no COC was reported twice, two were reported three times, two were reported four times, four were reported five times and one COC was reported six times by participants.

From the reported COCs some are explicated by majority of the participants in both groups. For example, isomers differ in their structures (50\%CG:100\% IG); isomers have the same molecular formula (50\%CG: $83 \% \mathrm{IG})$; alkanes show structural isomerism (50\%CG:83\%IG); alkynes show structural isomerism (17\%CG:83\% IG); alkenes 
Table 4. Alternative conceptions experienced by CG and IG students after intervention on isomerism of AHs

\begin{tabular}{|c|c|c|}
\hline AC of CG & AC of IG & Freq. \\
\hline \multicolumn{3}{|c|}{ Alternative conceptions involving Language (ACs-Lang) } \\
\hline 1. Alkanes show $\mathrm{n}$-isomerism & $1 \quad 1$. Isomers are confused with isotopes & 1 \\
\hline 2. Alkanes show neo-isomerism & 1 & \\
\hline 3. Alkanes show iso-isomerism & 1 & \\
\hline \multicolumn{3}{|c|}{ Alternative Conceptions involving Prior Knowledge (ACs-Prior K) } \\
\hline $\begin{array}{l}\text { 4. Isomerism is group of atoms having the same } \\
\text { physical properties }\end{array}$ & 2. Alkanes exhibit geometric isomerism characteristically & 3 \\
\hline 5. Alkynes show geometric isomerism & 3. Alkynes show geometric Isomerism & 2 \\
\hline 6. Alkanes exhibit geometric isomerism & 2 & \\
\hline $\begin{array}{l}\text { 7. Isomer means a compound that shows } \\
\text { different structures in one formula }\end{array}$ & 1 & \\
\hline \multicolumn{3}{|c|}{ Other Cognitive aspect Alternative conceptions (OCog-asp-ACs) } \\
\hline 8. Alkynes do not show isomerism & 1 & \\
\hline Number of ACs & 8 & 3 \\
\hline Extensiveness of ACs & Extensiveness of $\mathrm{ACs}$ & 6 \\
\hline
\end{tabular}

show position isomerism (67\%CG:67\% IG) and alkenes show geometric isomerism (50\%CG:67\% IG). This showed that after intervention the pre-service chemistry teachers in the IG showed more COCs than those in the CG in isomerism concepts of AHs. The interview responses of participants (both in terms of ACs and COCs) from comparison and intervention group after intervention showed that during the posttest the pre-service chemistry teachers in the CCIA group had reduced ACs with understanding in isomerism related AHCs than those in CIA group.

Table 4 depicts alternative conceptions of AHs in relation to isomerism. In the two groups, there were 11 ACs. Eight ACs were in the comparison group and 3 were in the intervention group. Three ACs from 8 in the comparison group were ACs-Lang type, 5 were ACs-prior K type and no AC was reported on OCog-Asp-ACs type. One ACs was reported in relation to ACs-Lang type from 3 ACs in the intervention group, 2 ACs were reported on ACsprior K type and no OCog-Asp-AC was acquired by participants in this group. OCog-Asp-ACs were not reported in the groups. ACs-prior $\mathrm{K}$ type is dominant type in both groups. From eight Alternative Conceptions (ACs) reported from the comparison group pre-service chemistry teachers, six were reported only once, one AC was reported twice and another one AC was reported three times. Again, from three ACs reported from intervention group pre-service chemistry teachers, one AC was reported once, the other two ACs were reported twice and three times. From the reported alternative ACs some are explained by significant number of participants. For example, students in comparison group were with the opinion that Alkanes exhibit geometric isomerism. Two ( $33 \%$ ) of the participants from the comparison group and three (50\%) from intervention group were with this AC after intervention. Another noteworthy AC among participants from comparison group was related to isomerism in alkynes. For instance, participants from comparison group were with idea that alkynes show geometric isomerism. Three (50\%) of the participants from the comparison group were with this AC after intervention. Also, two (33\%) of the participants from intervention group were with the opinion that alkynes show geometric isomerism.

\section{Changes in Understanding Isomerism Related Aliphatic Hydrocarbon Concepts}

RQ3. Is there change in understanding isomerism related $\mathrm{AH}$ concepts after running conceptual change (through the use of CCTs) and conventional instructional approaches?

Pre-service chemistry teachers were again interviewed on questions related to isomerism of AHs before and after intervention. The interview response revealed that during the pretest pre-service chemistry teachers had comparative difficulty in describing and understanding isomerism of AHs. During the posttest the same students exhibited improved understanding. But the level of understanding is much better in the case of pre-service teacher from CCIA group participant. Owing to the analysis carried out, this section presents changes in isomerism related AHCs understanding of pre-service chemistry teachers (PCTs). The section is divided into three thematized subsections: definitional and structural features; features related to existence of isomerism and its typologies; and existence of isomerism and structural features.

\section{Definitional and Structural Features}

Appendix B offers summary of changes in isomerism related AHCs understanding of PCTs. In relation to this first theme several COCs and ACs were reflected from participants. For instance, before CIA three out of six participants (C-02, C-05 and C-06) in the CG reflected the idea "isomers have the same molecular formula". The 
same number of participants (C-02, C-03 and C-06) reflected the idea "isomers have the same molecular formula" after CIA. Here two participants (C-02 and C-06) reflected the same COC both before and after CIA. One participant (C-05) reflected the idea before CIA and another one participant (C-03) reflected the same idea after CIA.

Besides, two out of six participants (IP-01 and IP-06) in the IG reflected the idea that "isomers have the same molecular formula" before CCIA. After CCIA, five participants out of six (IP-01, IP-02, IP-04, IP-05 and IP-06) reflected the same idea. Here, analysis indicated the existence of better change in the IG because the two participants (IP-01 and IP-06) did not change the idea and more participants (IP-02, IP-04 and IP-05) came up with the same COC after CCIA. Only one participant (IP-04) reflected the COC "isomers can have different chemical properties" before CCIA.

In relation to the theme "definitional and structural features" the number of participants with ACs in CG increased from one to two since $\mathrm{C}-04$ reflected the $\mathrm{AC}$ "isomers have different molecular formula and mass" before CIA, and two participants (C-04 and C-05) acquired the ACs "isomerism is group of atoms having the same physical properties" and "isomer means a compound that shows different structures in one formula" respectively.

In addition, the number of participants with ACs in IG decreased from three to one as IP-01, IP-02 and IP-03 reflected ACs "isomers are compounds with the same structures but different molecular formulas", "isomers can be changed in to the other isomeric forms through physical manipulation of a given structure" and "isomers have different molecular formula and mass" respectively before CCIA. Participants IP-02 and IP-01 did not reflect other or the same ACs after CCIA but participant IP-03 reflected other AC after CCIA. The full account of interview data from each PCT participant in the groups (CG and IG) indicated better change in the IG in terms of "isomerism related definitional and structural features" but with wavering nature of some conceptions in the groups.

\section{Features Related to Existence of Isomerism and its Typologies}

Also, Appendix B encompasses "features related to existence of isomerism and its typologies" theme as part of changes in isomerism related AHCs understanding with different ideas. In relation to this second theme several COCs and ACs were reflected from participants. For instance, before CIA one participant (C-02) in the CG reflected the COC "alkenes show geometric isomerism". Three out of six CG participants (C-01, C-02 and C-04) reflected the same COC after CIA. Here one participant, participant-02, reflected the same COC both before and after CIA but two participants (C-01 and C-04) reflected the same COC only after CIA indicating change.

In addition, two of six participants (IP-04 and IP-05) in the IG reflected the COC "alkenes show geometric isomerism" before CCIA. After CCIA, four participants out of six (IP-01, IP-02, IP-03 and IP-04) echoed the same COC. One participant, participant-IP-04, reflected the same COC before and after CCIA but three participants (IP01, IP-02 and IP-03) mirrored the same COC only after CCIA indicating change.

What is more, two participants out of six (C-01 and C-02) in the CG reflected the COC "alkenes show position isomerism" before CIA. After CIA, four out of six participants (C-01, C-02, C-04 and C-05) echoed the same COC. Moreover, two out of six participants (IP-03 and IP-06) in the IG reflected the COC "alkenes show position isomerism" before CCIA. After CCIA, four out of six participants (IP-01, IP-02, IP-04 and IP-06) reflected the same COC. Here, participant IP-06 reflected the same COC both before and after CCIA but Participants IP-01, IP-02 and IP-04 reflected the same COC only after CCIA indicating change.

In relation to the other (other than the ones discussed earlier) "existence of isomerism and its typological features" related COCs, in the CG eight COCs were reflected by participants both before and after intervention with aggregate frequencies ten and thirteen respectively. In CG one participant (C-04); two participants (C-01 and C-04); two participants again (C-01 and C-04); one participant (C-01); one participant again (C-03); two participants (C-01 and C-02); one participant (C-05) and one participant again (C-05) echoed the COCs "alkanes exhibit isomerism", "alkenes exhibit isomerism", "alkynes exhibit isomerism", "alkynes show position isomerism", "alkanes show structural isomerism", "alkenes show structural isomerism", "alkenes exhibit chain isomerism", and "alkynes exhibit chain isomerism" respectively before CIA. Also, in the CG two participants (C-01 and C-04); three participants (C-01, C-02 and C-04); two participants (C-03 and C-04); two participants again (C-02 and C-05); one participant (C-05), the same one participant (C-05); one participant (C-01) and another one participant (C-04) echoed the COCs "alkynes show position isomerism", "alkanes show structural isomerism", "alkenes show structural isomerism", "alkanes show position isomerism", "alkenes exhibit chain isomerism", "alkynes exhibit chain isomerism", cyclic alkanes show geometric isomerism" and "alkynes show structural isomerism" respectively after CIA.

Moreover, in relation to other "existence of isomerism and its typological features" related COCs, in the IG five and eight COCs were reflected by participants before CCIA and after CIA with aggregate frequencies eight and twenty-four respectively. In the IG two participants (IP-01 and IP-02); two participants again (IP-02 and IP-04); the same two participants (IP-02 and IP-04); one participant (IP-02) and another one participant (IP-05) revealed the COCs "alkanes exhibit isomerism", "alkenes exhibit isomerism", "alkynes exhibit isomerism", "alkynes show 
Table 5. Summary of correct conceptions of groups in Isomerism related concepts of AHs

\begin{tabular}{ccccccccc}
\hline Area of Focus & Group & COC-pre & COC-post & COC-Gain & Ext-COC pre & Ext-COC post & Ext- Gain \\
\hline \multirow{2}{*}{ Isomerism } & CG & 14 & 14 & 0 & 22 & 28 & +6 \\
\cline { 2 - 9 } & IG & 12 & 13 & +1 & 20 & 44 & +24 \\
\hline
\end{tabular}

position isomerism" and "alkanes show position isomerism" respectively before CCIA. After CCIA, one IG participant (IP-01); the same one participant (IP-01); three participants (IP-01, IP-02 and IP-06); five participants (IP01, IP-02, IP-04, IP-05 and IP-06); five participants again (IP-01, IP-02, IP-03, IP-05 and IP-06); three participants (IP02, IP-04 and IP-06), one participant (IP-02) and five participants (IP-01, IP-02, IP-03, IP-05 and IP-06) echoed the COCs "alkenes exhibit isomerism", "alkynes exhibit isomerism", "alkynes show position isomerism", "alkanes show structural isomerism", "alkenes show structural isomerism", "alkanes show position isomerism", cyclic alkanes show geometric isomerism" and "alkynes show structural isomerism" respectively indicating better change.

In relation to the theme "existence of isomerism and its typological features" the number of participants in CG with aggregate ACs frequencies increased from six to nine since C-04; C-04 (again); C-03 and C-04; C-03, and C-01 reflected the ACs " alkanes exhibit polymerization isomerism"; "alkanes exhibit linkage isomerism"; "alkanes exhibit linkage isomerism"; "alkanes exhibit ligand isomerism" and "alkanes have position isomers with double bonds" respectively before CIA totaling six aggregate frequencies. Also, participants C-02; C-03; C-03 (again); C-03 (similarly); C-01, C-04 and C-05; and C-02 and C-05 mirrored the ACs " alkynes do not show isomerism"; "alkanes show n-isomerism; "alkanes show neo-isomerism"; "alkanes show iso-isomerism"; "alkynes show geometric isomerism" and "alkanes show geometric isomerism" respectively before CIA totaling nine aggregate frequencies.

Also, the number of participants with ACs in IG decreased from four (six aggregate frequencies) to two (five aggregate frequencies) as IP-06, IP-06 (again); IP-04, IP-05 and IP-06; and IP-06 reflected ACs "alkanes exhibit linkage isomerism"; "alkanes exhibit hydration isomerism"; "alkynes show geometric isomerism"; and "alkanes exhibit geometric isomerism" respectively before CCIA and participants IP-05 and IP-06; and IP-02, IP-03 and IP06 mirrored the ACs "alkynes show geometric isomerism"; and "alkanes exhibit geometric isomerism" respectively after CCIA indicating better change in the group.

\section{Existence of Isomerism and Structural Features}

Again, Appendix B includes "existence of isomerism and structural features" theme as part of changes in isomerism related AHCs understanding with different ideas. In relation to this third theme two COCs were reflected from participants. For example, before CIA one participant (C-03) in the CG reflected the COCs "alkenes show isomerism due to structural difference" and "alkynes show isomerism due to structural difference". No correct COCs of this sort was reflected by CG participants after CIA. Also, before CCIA one participant (IP-03) in the IG reflected the same COCs "alkenes show isomerism due to structural difference" and "alkynes show isomerism due to structural difference". One Participant (IP-01) echoed the COC "alkenes show isomerism due to structural difference". The results here indicate the varying nature of PCTs conceptions but the CCIA group with one COC after intervention made better improvement.

Generally, the interview responses obtained from the pre-service chemistry teachers indicate that these respondents had COCs and ACs about the isomerism of AHs. In all the three isomerism related themes (definitional and structural features; features related to existence of isomerism and its typologies; and existence of isomerism and structural features) CCIA group made meaningful change. However, there is varying nature of Ideas. This may lead us to the conclusion that the pre-service teachers in treatment/intervention group had much better understanding than those in the comparison group in isomerism related concepts of AHs.

Table 5 shows that prior to intervention the comparison group participants experienced 14 COCs in total but after intervention/CIA they experienced 14 which shows, there is no improvement in understanding isomerism related $\mathrm{AH}$ concepts. Also, the same table depicts that the extensiveness of the same group participants-22 before CIA and 28 after CIA. Extensiveness of COCs showed improvement of 6 in the group.

Prior to intervention, the intervention group participants experienced 12 COCs but after intervention/CCIA they experienced 13 COCs, which shows there is improvement in understanding AH concepts. Also, the same table depicts that the extensiveness of the intervention group participants with much improvement: 20 before CCIA and 44 after CCIA. Extensiveness of COCs showed improvement of 24, which is much higher than the CIA group value. Table 6 shows that prior to intervention the comparison group participants experienced 6 ACs but after intervention/CIA they experienced 8 which shows, there is no improvement in understanding isomerism related AHCs. Also, the same table depicts that the extensiveness of the same group participants. Extensiveness of ACs shows no improvement as the participants extensiveness was 7 before intervention and 11 after intervention. Prior 
Table 6. Summary of ACs and extensiveness in relation to isomerism related concepts of AHs

\begin{tabular}{ccccccccc}
\hline Area of Focus & Group & AC-pre & AC-post & AC-Gain or CC* & Ext-pre & Ext-post & Ext-Gain or CC* \\
\hline \multirow{2}{*}{ Isomerism } & CG & 6 & 8 & -2 & 7 & 11 & -4 \\
& IG & 7 & 3 & +4 & 9 & 6 & +3 \\
\hline
\end{tabular}

$C C^{*}=$ conceptual change-indicated using plus sign (+) when there is decrease in AC frequency and extensiveness. It is indicated using minus sign (-) when there is increase in AC freq. and ext.

to intervention, the intervention group participants experienced 7 ACs but after intervention/CCIA they experienced 3, which shows there is improvement in understanding isomerism related AHCs.

Also, the same table depicts that the extensiveness of the intervention group participants was with improvement. Extensiveness of ACs was 9 before intervention and 6 after CCIA. There is improvement in the intervention group both in terms of number of ACs and extensiveness. The interview responses of participants (both in terms of ACs and COCs) from comparison and intervention group after intervention showed that during the posttest the pre-service chemistry teachers in the CCIA group had reduced ACs with understanding in isomerism related $\mathrm{AH}$ concepts than those in CIA group.

\section{DISCUSSION}

Understanding problems/alternative conceptions of aliphatic hydrocarbons in relation to isomerism were reported in the findings of this study. The groups differ in terms of isomerism related concepts after intervention. For instance, $50 \%$ of IG members were with the AC alkynes show geometric isomerism before intervention. After intervention the IG had the same ACs but the percentage changed to $33 \%$. The finding here concords with the findings of other studies (Hassan, Hill \& Reid, 2004; Omwirhiren \& Ubanwa, 2016; Sendur, 2012; Sendur \& Toprak, 2013). For instance, Hassan et al. (2004) reported that a great majority of students in the introductory course in organic chemistry had difficulty in describing geometric isomers of molecules. These findings are also in agreement with the findings of Omwirhiren and Ubanwa (2016). Omwirhiren and Ubanwa (2016) have found that Nigerian students had difficulties with ACs in Isomerism. In this study, in terms of extensiveness, much improvement was observed in the IG in relation to isomerism of AH concepts. The interview responses obtained from the pre-service chemistry teachers indicate that these respondents had ACs about the isomerism of AHs. After the treatment the ACs decreased on the side of CCIA participant indicating improved level of understanding. Scientifically correct ideas were reflected during the interview by this participant. The COCs reflected from participants indicated better improvement in the IG in relation to isomerism.

\section{CONCLUSION}

This section of the article draws together the results of the study. The results in this article were based on three research questions. Before CCIA and CIA, participants were asked about isomerism related concepts of AHCs using semi-structured interview protocol. After intervention, data were gathered using the same instrument and analyses were made. Analyses of the result revealed that the IG/CCIA group outperformed the CG/CIA group in isomerism related concepts. That is, the PCTs in CCIA group had better understanding-with reduced ACs and improved COCs in these concepts. In this study, meaningful result was obtained in the IG confirming the superiority of CCIA over CIA.

\section{REFERENCES}

Alvermann, D. E., \& Hague, S.A. (1989). Comprehension of counter-intuitive science text: Effects of prior knowledge and text structure. Journal of Educational Research, 82, 197-202. https://doi.org/10.1080/00220671.1989.10885893

Ary, D., Jacobs, L. C., Sorensen, C., \& Razavie, A. (2010). Introduction to research in education (8 ${ }^{\text {th }}$ Ed.). Australia. Wadsworth, Cengage Learning.

Baser, M. (2006). Fostering Conceptual Change by Cognitive Conflict Based Instruction on Students' Understanding of Heat and Temperature Concepts. Eurasia Journal of Mathematics, Science and Technology Education, 2(2), 96114. https:// doi.org/10.12973/ ejmste/75458

Baser, M., \& Geban, Ö. (2007). Effectiveness of conceptual change instruction on understanding of heat and temperature concepts. Research in Science $\mathcal{E}$ Technological Education, 25(1), 115-133. https:/ / doi.org/10.1080/02635140601053690

Brooks, J. G., \& Brooks, M. G. (1993). In search of understanding: The case for constructivist classrooms. Alexandria, VA: Association of Supervision and Curriculum Development. 
Bryan, L. C. H. (2007). Identifying students' Misconceptions in "A- level" Organic Chemistry. Journal of Chemical Education. Retrieved on 15 January 2016 from http:/ /jchemed.chem.wise.edu/JCEDLib/ConceptsInven

Clement, J. (2008). The role of explanatory models in teaching for conceptual change. In S. Vosniadou (Ed.), International handbook of research on conceptual change (pp. 417-452). New York: Routledge.

Duffy, T. M., \& Jonassen, D. H. (1991). New implications for instructional technology? Educational Technology, 31(3), 7-12.

Gale, N. K., Heath, G., Cameron, E., Rashid, S., \& Redwood, S. (2013). Using Framework Method for Analysis of Qualitative Data in Multi-disciplinary Health Research. Medical Research Methodology, 13(117), 1-8. https:/ / doi.org/10.1186/1471-2288-13-117

Gilbert, J. K., Watts, D. M., \& Osborne, R. J. (1985). ‘Eliciting student views using an interview-about-instances technique'. In C. West and A. Pines (eds.), Cognitive structure and conceptual change (pp. 11-27). Orlando, FL: Academic Press

Gorodetsky, M., \& Keiny, S. (2002). Participative learning and conceptual change. In M. Limon and L. Mason (Eds.), Reconsidering conceptual change: Issues in theory and practice (149-164). New York: Kluwer Academic. https://doi.org/10.1007/0-306-47637-1_8

Govender, N., \& Bekele Dega (2016). Framework categorization of pre-service physics teachers' conceptions of vector-kinematics. Journal of Baltic Science Education, 15(3), 325-339.

Graesser, A. C., Leon, J. A., \& Otero, J. (2002). Introduction to the Psychology of Science Text Comprehension. In A.C. Graesser, J. A. Leon, and J. Otero (Eds.), The psychology of science text comprehension (pp. 1-18). London: Lawrence Erlbaum.

Guzzetti, B. J, Williams, W. O., Skeels, S. A., \& Wu, S. M. (1997). Influence of text structure on learning counterintuitive physics concepts. Journal of Research in Science Teaching, 34, 701-719 https:/ / doi.org/10.1002/(SICI)1098-2736(199709)34:7<701::AID-TEA3>3.0.CO;2-Q

Harrison, A. G., \& Treagust, D. F. (2000). Learning about Atoms, Molecules, and Chemical Bonds: A Case Study of Multiple-Model Use in Grade 11. Chemistry. Sci. Educ., 84(3), 352-381. https:/ / doi.org/10.1002/(SICI)1098237X(200005)84:3<352::AID-SCE3>3.0.CO;2-J

Hassan, A., Hill, R., \& Reid, N. (2004). Ideas underpinning success in an introductory course in organic chemistry. University Chemistry Education, 8(2), 40-51.

Hatch, J. A. (2002). Doing qualitative research in education settings. USA: State University of New York Press.

Jhonstone, A. H. (2006). Chemical Education Research in Glasgow in perspective. Chemical Education Research and Practice, 7(2), 49-63. https:/ / doi.org/10.1039/B5RP90021B

Jhonstone, A. H. (2010). You can't get there from here. Journal of Chemical Education, 87(7), $22-29$. https:// doi.org/10.1021/ed800026d

Kuhn, T. S. (1962). The structure of scientific revolutions. Chicago: Chicago Press.

Kuzel, A. J. (1992). Sampling in qualitative inquiry. In B.F. Crabtree, W.L. Miller, (Eds.), Doing qualitative research (pp. 31-44). Newbury Park, CA: Sage.

Luborsky, M. R., \& Rubinstein, R. L. (1995). Sampling in qualitative research. Res. Aging, 17, 89-113. https:/ / doi.org/10.1177/0164027595171005

Lyons, L. L., Freitag, P. K., \& Hewson, P. W. (1997). Dichotomy in Thinking, Dilemma in Actions: Researcher and Teacher Perspectives on a Chemistry Teaching Practice. Journal of Research in Science Teaching, 34(3), $239-254$. https:/ / doi.org/10.1002/(SICI)1098-2736(199703)34:3<239::AID-TEA3>3.0.CO;2-T

Maria, K., \& MacGinitie, W. (1987). Learning from texts that refute the reader's prior knowledge. Reading Research and Instruction, 26, 222-238. https://doi.org/10.1080/19388078709557912

Mayer, R. E. (2002). Understanding Conceptual Change: A Commentary. In M. Limon and L. Mason (Eds.), Reconsidering conceptual change: Issues in theory and practice (101-114). New York: Kluwer Academic. https://doi.org/10.1007/0-306-47637-1_5

Mulford, D. R., \& Robinson, W. R. (2002). An inventory for alternate conceptions among first-semester general chemistry students. Journal of Chemical Education, 79(6), 739-744. https:/ / doi.org/10.1021/ed079p739

O'Dwyer, A., \& Childs, P.E. (2017). Who says organic chemistry is difficult? Exploring Perspectives and Perceptions. EURASIA Journal of Mathematics Science and Technology Education, 13(7), 3599-3620. https:/ / doi.org/10.12973/eurasia.2017.00748a

Omwirhiren, E. M., \& Ubanwa, A. O. (2016). An analysis of misconceptions in organic chemistry among selected senior secondary school students in Zaria local government area of Kaduna state, Nigeria. International Journal of Education and Research, 4(7), 247-266. 
Osman, K. (2017). Addressing Secondary School Students' Misconceptions about Simple Current Circuits Using the Learning Cycle Approach. In M. Karpudewan, A.N. Zain and A.L. Chandrasegaran (Eds.), Overcoming Students' Misconceptions in Science: Strategies and Perspectives from Malaysia (pp. 223-242), Singapore: Springer https:/ / doi.org/10.1007/978-981-10-3437-4_12

Özkan, D., \& Selçuk, G. S. (2012). How effective is "conceptual change approach" in teaching Physics? Journal of educational and Instructional Studies in the World, 2(2), 182-190

Rabiee, F. (2004). Focus-group interview and data analysis. Proceedings of the Nutrition Society, 63, 655-660. https:/ / doi.org/10.1079/PNS2004399

Ritchie, J., \& Spencer, L. (1994). Qualitative data analysis for applied policy research. In A. Bryman and R.G. Burgess (Eds.), Analyzing Qualitative Data (pp. 173-194). London: Routledge. https:/ / doi.org/10.4324/9780203413081_chapter_9

Roth, K. J. (1986). Conceptual change learning and student processing of science texts (research ser. no. 167). East Lansing, MI: Michigan State University, Institute for Research on Teaching.

Schmidt, H. J. (1992). Conceptual Difficulties with Isomerism. Journal of research in Science Teaching, 29(9), 995-1003. https:/ / doi.org/10.1002/tea.3660290908

Sendur, G. (2012). Prospective science teachers' misconceptions in organic chemistry: The case of alkenes. Journal of Turkish Science Education, 9(3), 186-190.

Sendur, G. (2012). Prospective science teachers' misconceptions in organic chemistry: The case of alkenes. Journal of Turkish Science Education, 9(3), 186-190.

Sendur, G., \& Toprak, M. (2013). The role of conceptual change texts to improve students' understanding of alkenes. Chem. Edu. Res. Prac., 14, 431-449. https:// doi.org/10.1039/C3RP00019B

She, H. C. (2003). DSLM Instructional Approach to Conceptual Change Involving Thermal Expansion. Research in Science and Technological Education, 21(1), 43-54. https:/ / doi.org/10.1080/02635140308345

Shenton, A. K. (2004). Strategies for Insuring Trustworthiness in Qualitative Research Projects. Education for Information, 22, 63-75. https:/ / doi.org/10.3233/EFI-2004-22201

Singer, S. R., Nielsen, N. R., \& Schweingruber, H. A. (Eds.) (2012). Discipline-Based Education Research: Understanding and Improving Learning in Undergraduate Science and Engineering. USA: National Academy of Sciences

Skelly, K. M. (1993). The Development and Validation of a Categorization of Sources of Misconceptions in Chemistry. In proceedings of the third international seminar on misconceptions and educational strategies in science and mathematics, Misconception Trust: Ithaca, NY.

Sobal, J. (2001). Sample Extensiveness in Qualitative Nutrition Education Research, JNE, 33, $184-192$. https:/ / doi.org/10.1016/S1499-4046(06)60030-4

Solomon Areaya (2008). Policy formulation curriculum development and implementation in Ethiopia. Addis Ababa: Book centre of Addis Ababa University.

Swafford, D. J. (1989). The effects of a science text and demonstrations on conceptual change of high school students (Unpublished Doctoral Dissertation), University of Georgia, Athens, GA.

Sweeney, A. E., Bula, O. A., \& Cornett, J. W. (2001). The role of personal practice theories in the professional development of a beginning high school chemistry teacher. Journal of Research in Science Teaching, 30(4), 408441. https:// doi.org/10.1002/tea.1012

Taagepera M., \& Noori S. (2000). Mapping Students' Thinking Patterns in Learning Organic Chemistry by the Use of Knowledge Space Theory. J. Chem. Educ., 77(9), 1224-1229. https:/ / doi.org/10.1021/ed077p1224

Tam, M. (2000). Constructivism, instructional design, and technology: Implications for transforming distance learning. Educational Technology and Society, 3(2), 50-60.

Tyson, L. M., Venville, G. J., Harrison, A. L., \& Treagust, D. F. (1997). A multidimensional framework for interpreting conceptual change events in the classroom. Science Education, 81, 387-404. https:/ / doi.org/10.1002/(SICI)1098-237X(199707)81:4<387::AID-SCE2>3.0.CO;2-8

Vosniadou, S. (2007). Conceptual change and education. Human Development, 50(1), 47-54. https://doi.org/10.1159/000097684

Vosniadou, S., \& Skopeliti, I. (2014). Conceptual Change from the Framework Theory Side of the Fence. Sci \& Educ., 23, 1427-1445. https:// doi.org/10.1007/s11191-013-9640-3

Wylie, J., \& McGuinness, C. (2004). The interactive effects of prior knowledge and text structure for cognitive psychology texts. British Journal of Educational Psychology, 74, 497-514. https://doi.org/10.1348/0007099042376418 


\section{APPENDIX A}

\section{Semi-structured Interview Protocol for Isomerism related AHCs}

Thank you for agreeing to be interviewed. I am doing this interview to explore students' understanding of aliphatic hydro carbon concepts in relation to the article entitled: "NUDGING COLLEGE STUDENTS TOWARD THE DESIRED PATH IN ISOMERISM CONCEPTS OF ALIPAHTIC HYDROCARBONS THROUGH THE USE OF CONCEPTUAL CHANGE TEXTS". The data obtained from this interview will be transcribed and used for academic purpose. Everything you say will be strictly confidential. Your name will not be included in the written transcript of this study. We will stick to isomerism related aliphatic hydrocarbon concepts in this interview. This interview will take 10-20 minutes (approximately). If you would prefer not to answer any of the questions during the interview just let me know and we will move on to the next question. It is possible to stop at any time during the interview if you want not to give ideas. Is this good idea?

\section{Informed Consent}

Do you have any question before we start? Do you agree to participate in this interview?

\section{Interview Items}

1. What are Isomers? Explain please.

2. What type (s) of isomerism is exhibited by Alkanes? Explain please.

3. Do Alkenes and Alkynes exhibit Isomerism? What type (s) of isomerism is exhibited by alkenes and alkynes? Could you explain your idea by providing examples?

\section{APPENDIX B}

\section{Changes in Understanding of Isomerism}

\begin{tabular}{|c|c|c|c|c|c|c|c|c|c|}
\hline \multirow{3}{*}{ Theme } & \multirow{3}{*}{ Idea manifested } & \multicolumn{4}{|c|}{ CG Participants } & \multicolumn{4}{|c|}{ IG Participants } \\
\hline & & \multicolumn{2}{|c|}{$\mathrm{CC}$} & \multicolumn{2}{|c|}{ AC } & \multicolumn{2}{|c|}{$\mathrm{CC}$} & \multicolumn{2}{|c|}{$\mathrm{AC}$} \\
\hline & & Pre & post & Pre & post & Pre & post & Pre & post \\
\hline \multirow{9}{*}{$\begin{array}{l}\text { Definitional } \\
\text { and } \\
\text { structural } \\
\text { features }\end{array}$} & Isomers have the same molecular formula & $\begin{array}{l}\text { C-02, } \\
\text { C-05, } \\
\text { C-06 }\end{array}$ & $\begin{array}{l}\text { C-02, } \\
\text { C-03, } \\
\text { C-06 }\end{array}$ & - & - & $\begin{array}{l}\text { IP-01, } \\
\text { IP-06 }\end{array}$ & $\begin{array}{l}\text { IP-01, } \\
\text { IP-02, } \\
\text { IP-04, } \\
\text { IP-05, } \\
\text { IP-06 }\end{array}$ & - & - \\
\hline & Isomers differ in their structures & $\begin{array}{l}\text { C-02, } \\
\text { C-03, } \\
\text { C-05 }\end{array}$ & $\begin{array}{l}\text { C-03, } \\
\text { C-05, } \\
\text { C-06 }\end{array}$ & - & - & $\begin{array}{l}\text { IP-01, } \\
\text { IP-04, } \\
\text { IP-06 }\end{array}$ & $\begin{array}{l}\text { IP-01, } \\
\text { IP-02, } \\
\text { IP-03, } \\
\text { IP-04, } \\
\text { IP-05, } \\
\text { IP-06 }\end{array}$ & - & - \\
\hline & $\begin{array}{l}\text { Isomers can have different chemical } \\
\text { properties }\end{array}$ & - & - & - & - & IP-04 & - & - & - \\
\hline & $\begin{array}{l}\text { Isomers are compounds with the same } \\
\text { structures but different molecular formula }\end{array}$ & - & - & - & - & - & - & IP-02 & - \\
\hline & $\begin{array}{l}\text { Isomers can be changed into the other } \\
\text { isomeric forms through physical } \\
\text { manipulation of a given structure } \\
\text { (Neopentane can be changed in to a } \\
\text { different structure) }\end{array}$ & - & - & - & - & - & - & IP-01 & - \\
\hline & $\begin{array}{l}\text { Isomers have different molecular formula } \\
\text { and mass }\end{array}$ & - & - & C-04 & - & - & - & IP-03 & - \\
\hline & Isomers are confused with isotopes & - & - & - & - & - & - & - & IP-03 \\
\hline & $\begin{array}{l}\text { Isomerism is group of atoms having the } \\
\text { same physical properties }\end{array}$ & - & - & - & C-04 & - & - & - & - \\
\hline & $\begin{array}{l}\text { Isomer means a compound that shows } \\
\text { different structures in one formula }\end{array}$ & - & - & - & C-05 & - & - & - & - \\
\hline
\end{tabular}


Belachew / Nudging College Pre-service Teachers towards

\begin{tabular}{|c|c|c|c|c|c|c|c|c|c|}
\hline \multirow{3}{*}{ Themes } & \multirow{3}{*}{ Idea manifested } & \multicolumn{4}{|c|}{ CG Participants } & \multicolumn{4}{|c|}{ IG Participants } \\
\hline & & \multicolumn{2}{|c|}{$\mathrm{CC}$} & \multicolumn{2}{|c|}{ AC } & \multicolumn{2}{|c|}{$\mathrm{CC}$} & \multicolumn{2}{|c|}{$\mathrm{AC}$} \\
\hline & & Pre & post & Pr & Po & Pre & post & Pre & post \\
\hline \multirow{13}{*}{$\begin{array}{l}\text { Existence of } \\
\text { isomerism } \\
\text { and its } \\
\text { typological } \\
\text { features }\end{array}$} & Alkanes exhibit isomerism & C-04 & - & - & - & $\begin{array}{l}\text { IP-01, IP- } \\
02\end{array}$ & - & - & - \\
\hline & Alkenes exhibit isomerism & $\begin{array}{c}\text { C-01, C- } \\
04\end{array}$ & - & - & - & $\begin{array}{c}\text { IP-02, IP- } \\
04 \\
\end{array}$ & IP-01 & - & - \\
\hline & Alkynes exhibit isomerism & $\begin{array}{c}\text { C-01, C- } \\
04 \\
\end{array}$ & - & - & - & $\begin{array}{c}\text { IP-02, IP- } \\
04 \\
\end{array}$ & IP-01 & - & - \\
\hline & Alkenes show geometric isomerism & C-02 & $\begin{array}{l}\text { C-01 C- } \\
02, \mathrm{C}-04\end{array}$ & - & - & $\begin{array}{c}\text { IP-04, IP- } \\
05\end{array}$ & $\begin{array}{c}\text { IP-01, IP- } \\
\text { 02,IP-03, } \\
\text { IP-04 }\end{array}$ & - & - \\
\hline & Alkenes show position isomerism & $\begin{array}{l}\text { C-01, C- } \\
03\end{array}$ & $\begin{array}{c}\text { C-01, C- } \\
02, \mathrm{C}- \\
04, \mathrm{C}-05\end{array}$ & - & - & $\begin{array}{l}\text { IP-03, IP- } \\
06\end{array}$ & $\begin{array}{c}\text { IP-01, IP- } \\
\text { 02, IP-04, } \\
\text { IP-06 }\end{array}$ & - & - \\
\hline & Alkynes show position isomerism & C-01 & $\begin{array}{l}\text { C-01, C- } \\
04\end{array}$ & - & - & IP-02 & $\begin{array}{l}\text { IP-01, IP- } \\
\text { 02, IP-06 }\end{array}$ & - & - \\
\hline & Alkanes show structural isomerism & C-03 & $\begin{array}{l}\text { C-01, C- } \\
02, \mathrm{C}-04\end{array}$ & - & - & - & $\begin{array}{c}\text { IP-01, IP- } \\
\text { 02, IP-04, } \\
\text { IP-05, IP- } \\
06\end{array}$ & . & - \\
\hline & Alkenes show structural isomerism & $\begin{array}{c}\text { C-01,C- } \\
02\end{array}$ & $\begin{array}{l}\text { C-03, C- } \\
04\end{array}$ & - & - & - & $\begin{array}{c}\text { IP-01, IP- } \\
\text { 02, IP-03, } \\
\text { IP-05, IP- } \\
06\end{array}$ & . & - \\
\hline & Alkanes show position isomerism & - & $\begin{array}{c}\text { C-02, C- } \\
05\end{array}$ & - & - & IP-05 & $\begin{array}{l}\text { IP-02, IP- } \\
04, \text { IP-06 }\end{array}$ & - & - \\
\hline & Alkenes exhibit chain isomerism & C-05 & C-05 & - & - & - & - & - & - \\
\hline & Alkynes exhibit chain isomerism & C-05 & C-05 & - & - & - & - & - & - \\
\hline & $\begin{array}{l}\text { Cyclic alkanes show geometric } \\
\text { isomerism }\end{array}$ & - & C-01 & - & - & - & IP-02 & - & - \\
\hline & Alkynes show structural isomerism & - & C-04 & - & - & - & $\begin{array}{c}\text { IP-01, IP- } \\
\text { 02, IP-03, } \\
\text { IP-05, IP- } \\
06\end{array}$ & - & - \\
\hline \multirow{12}{*}{$\begin{array}{l}\text { Existence of } \\
\text { isomerism } \\
\text { and its } \\
\text { typological } \\
\text { features }\end{array}$} & $\begin{array}{l}\text { Alkane exhibit polymerization } \\
\text { isomerism }\end{array}$ & - & - & C-04 & - & - & - & - & - \\
\hline & Alkanes exhibit linkage isomerism & - & - & C-04 & - & - & - & IP-06 & - \\
\hline & Alkanes exhibit ionization isomerism & - & - & $\begin{array}{l}\text { C-03, C- } \\
04\end{array}$ & - & - & - & - & - \\
\hline & Alkanes exhibit ligand Isomerism & - & - & $\mathrm{C}-03$ & - & - & - & - & - \\
\hline & $\begin{array}{l}\text { Alkanes have position isomers with } \\
\text { double bonds }\end{array}$ & - & - & C-01 & - & - & - & - & - \\
\hline & Alkenes show hydration isomerism & - & - & - & - & - & - & IP-06 & - \\
\hline & Alkynes do not show isomerism & - & - & - & $\mathrm{C}-02$ & - & - & - & - \\
\hline & Alkanes show n-isomerism & - & - & - & C-03 & - & - & - & - \\
\hline & Alkanes show neo-isomerism & - & - & - & C-03 & - & - & - & - \\
\hline & Alkanes show iso-isomerism & - & - & - & C-03 & - & - & - & - \\
\hline & Alkynes show geometric isomerism & - & - & - & $\begin{array}{l}\text { C-01, C- } \\
04, C-05\end{array}$ & - & - & $\begin{array}{l}\text { IP-04, IP- } \\
\text { 05,IP-06 }\end{array}$ & $\begin{array}{l}\text { IP-06, IP- } \\
05 \\
\end{array}$ \\
\hline & Alkanes exhibit geometric isomerism & - & - & - & $\begin{array}{c}\text { C- }-02, C- \\
05\end{array}$ & - & - & IP-06 & $\begin{array}{l}\text { IP-03, IP- } \\
02, I P-06\end{array}$ \\
\hline \multirow{2}{*}{$\begin{array}{l}\text { Existence of } \\
\text { Isomerism } \\
\text { and } \\
\text { structural } \\
\text { features }\end{array}$} & $\begin{array}{l}\text { Alkenes show isomerism due to } \\
\text { structural difference }\end{array}$ & C-03 & - & - & - & IP-03 & IP-01 & - & - \\
\hline & $\begin{array}{l}\text { Alkynes show isomerism due to } \\
\text { structural difference }\end{array}$ & C-03 & - & - & - & IP-03 & - & - & - \\
\hline
\end{tabular}




\section{APPENDIX C}

\section{Sample Conceptual Change Text on Isomerism}

Which pairs show isomerism? Explain.

(I)

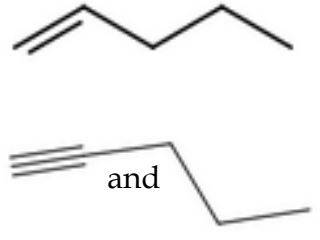

and

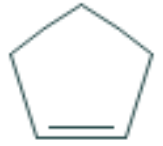

(II)
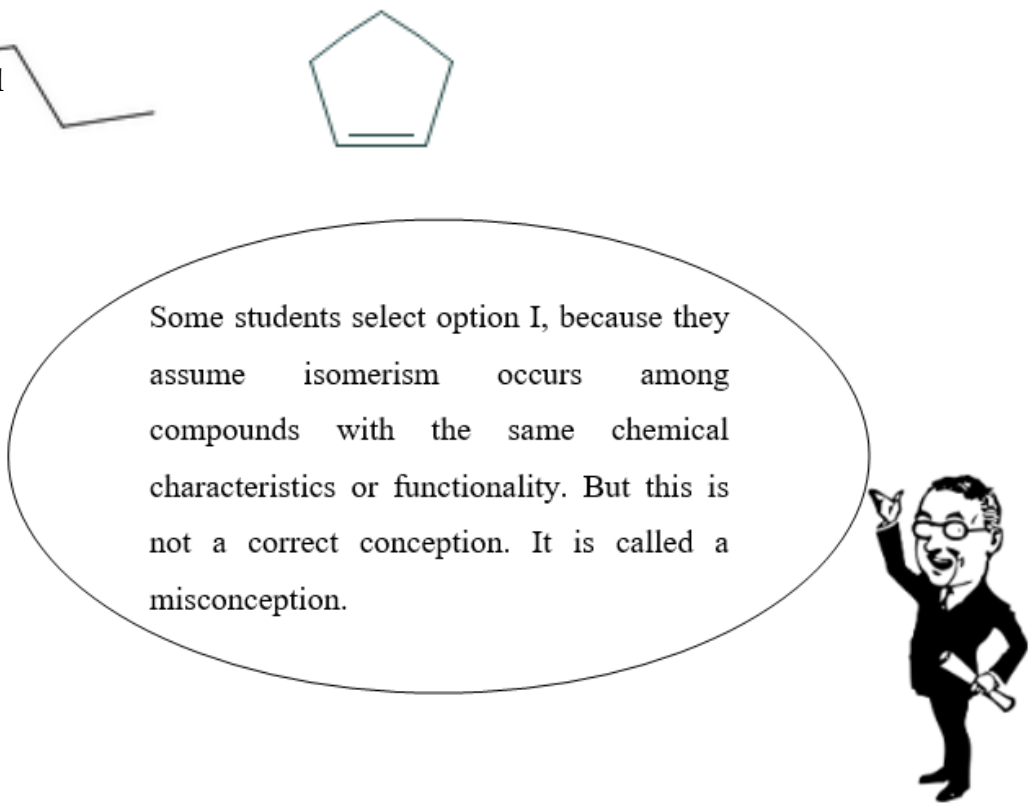

\section{Isomerism in Alkynes}

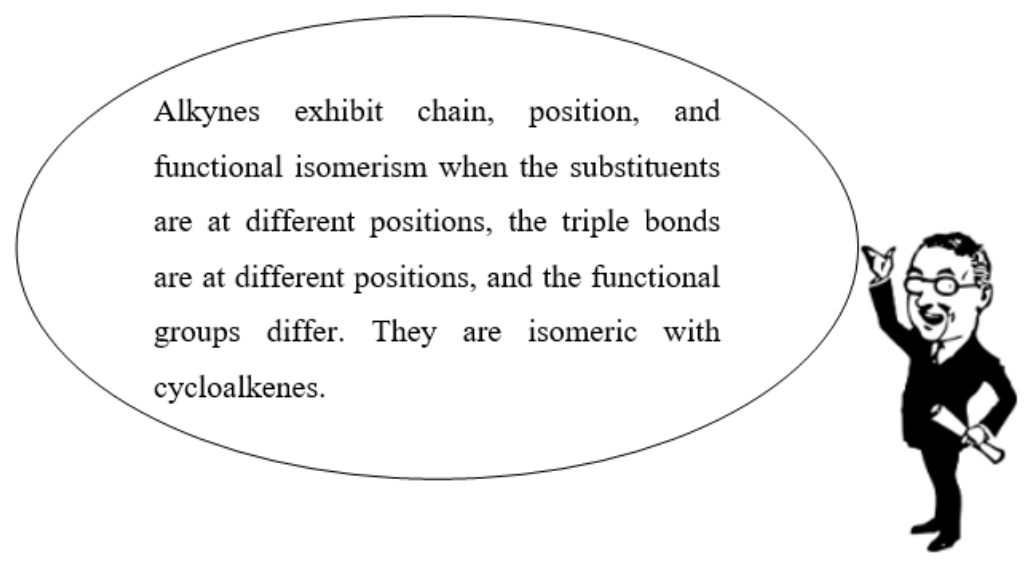


Examples:

1)

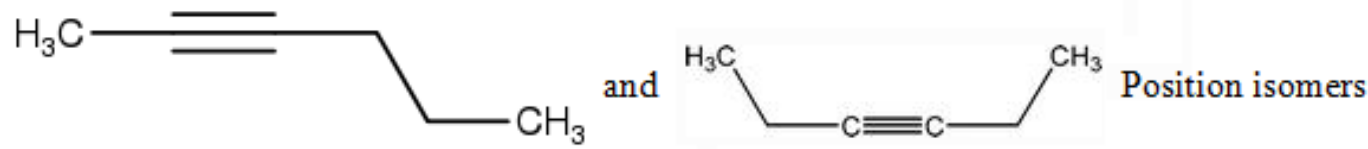

2)

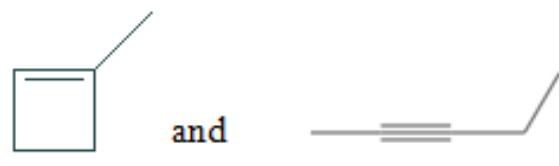

Functional isomers

3) $\mathrm{H}_{3} \mathrm{C}$<smiles>CC#CCCCC</smiles>

http://www.ejmste.com 